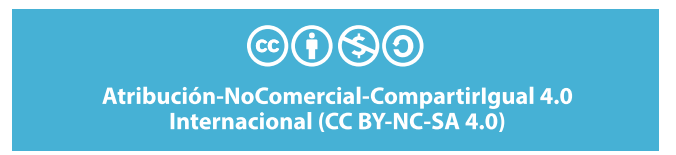

DOI: http://dx.doi.org/10.20983/reij.2021.2.1
Jaime Ernesto García Villegas ${ }^{1}$

Lila Maguregui Alcaráz $Z^{2}$
FECHA DE RECEPCIÓN: 13 de julio 2020

FECHA DE ACEPTACIÓN: 24 de noviembre 2020

\title{
REFLEXIONES SOBRE LA PRESCRIPCIÓN DE LA ACCIÓN PENAL DE CONFORMIDAD CON EL CÓDIGO NACIONAL DE PROCEDIMIENTOS PENALES
}

\author{
Reflections on the prescription of criminal action in accordance with the National Code \\ of Criminal Procedures
}

\section{Resumen}

El Código Nacional de Procedimientos Penales determina, en el artículo 211, que el ejercicio de la acción penal se inicia desde que el Ministerio Público solicita un citatorio para la programación de la audiencia inicial. Técnicamente se debería suspender la prescripción de la acción penal, toda vez que, a partir de ese momento, se debe considerar que existe una facultad ejercida por el órgano persecutor. Este criterio resulta distinto a la determinación que estaba contenida en el Código de Procedimientos Penales del Estado de Chihuahua, que establecía que la prescripción se interrumpía hasta el momento en que se realizaba la formulación de imputación, y no momentos previos, como lo era la solicitud de programación y citatorio. Por lo tanto, al haber perdido su vigencia el Código de Procedimientos Penales del Estado de Chihuahua, el Código Penal del Estado debe ajustar las disposiciones que se refieren a la figura de la prescripción y que se relacionan con el ejercicio de la acción penal, al criterio antes precisado, en virtud de que la parte sustantiva sigue precisando que la prescripción de la acción penal se interrumpe hasta que se lleva a cabo la comparecencia del imputado ante el juez de control (formulación de imputación), lo que puede generar problemas interpretativos y hacer nugatorio el derecho humano de acceso a la justicia de las víctimas u ofendidos.

Palabras clave: prescripción; acción penal; Principio de Especialidad; justicia.

1 Doctor en Derecho con Mención Honorífica por la Universidad Autónoma de Chihuahua. Abogado postulante y maestro de tiempo completo en la Facultad de Derecho de la Universidad Autónoma de Chihuahua. Se ha desempeñado como agente del Ministerio Público de la Fiscalía Encargada en Investigación y Persecución del Delito Zona Centro del Estado de Chihuahua, director general jurídico del Tribunal Superior de Justicia del Estado de Chihuahua, así como secretario de Sala Adscrito a Presidencia del mismo Tribunal. Colaborador del CA-UCH-57 de Derechos Humanos y Cultura de la Legalidad. Imparte cátedra, además de posgrados, en la Universidad La Salle y el Instituto de Seguridad Pública de la Fiscalía General del Justicia del Estado de Chihuahua.

2 Doctora en Administración Pública y profesora de tiempo completo en la Facultad de Derecho de la Universidad Autónoma de Chihuahua. Colaboradora del CA-UCH-57 de Derechos Humanos y Cultura de la Legalidad. 


\section{Abstract}

The National Code of Criminal Procedures determines in article 211 that the exercise of the criminal action begins from the moment the public prosecutor requests a summons for the scheduling of the initial hearing, which technically should suspend the prescription of the criminal action, every time that, from that moment on, it must be considered that there is a power exercised by the prosecuting body. This criterion is different from the determination that was contained in the Code of Criminal Procedures of the State of Chihuahua, which established that the prescription was interrupted until the moment in which the imputation was made, and not previous moments, such as the request for programming and summons. Therefore, since the Code of Criminal Procedures of the State of Chihuahua has lost its validity, the State Criminal Code must adjust the provisions that refer to the statute of limitations, and that relate to the exercise of criminal action, to the criterion previously specified, by virtue of the fact that the substantive part continues to specify that the prescription of the criminal action is interrupted until the appearance of the accused before the control judge (formulation of the accusation), which can generate interpretive problems and cause nugatory the human right of access to justice for victims or offended.

Keywords: prescription; criminal action; Principle of Specialty; justice.

\section{Introducción y consideraciones generales}

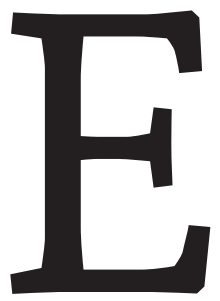

l objetivo de este trabajo es explicar y hacer una propuesta de solución para una antinomia dentro del sistema de procuración e impartición de justicia penal en México, toda vez que se analizarán las disposiciones sustantivas y adjetivas inherentes a la prescripción y al ejercicio de la acción penal. Por lo que se realizará un análisis detallado en torno a la regulación sobre el inicio del ejercicio de la acción penal, de conformidad con el Código Nacional de Procedimientos Penales; lo que permitirá contrastar los lineamientos adjetivos con las disposiciones locales sustantivas vigentes que se rela- 
cionan con esta figura, es decir, el Código Penal del Estado de Chihuahua, que incorpora el aspecto material sobre la prescripción de la referida acción.

De tal suerte que, en el trascurso de los parágrafos que integran este texto, se destacará cómo la codificación sustantiva penal de la entidad armoniza en realidad sobre dicho aspecto con el abrogado Código de Procedimientos Penales del Estado de Chihuahua; no obstante, discrepa en lo inherente al inicio del ejercicio de la pretensión punitiva con la Codificación Nacional Adjetiva de la materia. De tal suerte que, en este texto, se efectuará una propuesta interpretativa con los argumentos necesarios para resolver esta antinomia. Se abordará el tema desde los aspectos más generales, como anotaciones sobre la figura de las antinomias, la prescripción y, desde luego, la función persecutoria, hasta lo particular, como el conflicto entre las determinaciones sustantivas y adjetivas penales vigentes, para efecto de llevar a cabo adecuadamente el planteamiento del problema, así como la propuesta de la solución.

La función persecutoria del Ministerio Público, como lo apunta Rivera Silva (2005), tiene dos momentos: el primero se refiere a la investigación de los delitos y el segundo, al ejercicio de la acción penal, que consiste en una serie de gestiones que el órgano persecutor realiza ante los tribunales (p. 39). Con la finalidad de que se aplique la norma al caso concreto, ya sea imponiéndose una sanción, o bien, propiciando un medio alternativo de solución de conflictos, pero en todos los casos procurando la reparación integral del daño.

Por su parte, la prescripción, en su aspecto negativo, consiste en la pérdida de una facultad por el transcurso del tiempo; por lo tanto, la prescripción de la pretensión punitiva estriba en la extinción de esta, por haber transcurrido el tiempo establecido por la norma jurídica para que el Ministerio Público ejerza la misma, de tal suerte que el momento en que se debe tener por iniciado el ejercicio de la acción penal y la prescripción de esta guardan una íntima relación.

Martínez Morales (2014) puntualiza que la prescripción se traduce en el cese de la posibilidad que tiene el Estado de aplicar la ley a quien ha delinquido, por haber transcurrido el tiempo idóneo para ello, ya que por la prescripción se extinguen la acción penal y las sanciones (p. 640). Atentos a lo expuesto por Vela Treviño (1990),

[...] hay leyes generales que regulan el fenómeno de la prescripción, como es el caso de la legislación penal del Estado de Chihuahua, en realidad esas reglas están creando, además de una limitación al poder del Estado, una esfera de derechos a favor de los individuos, que tendrán, siempre, un derecho individual oponible 
al derecho general del Estado a perseguir los delitos y a los delincuentes (p. 51).

En relación con este punto, el Código Nacional de Procedimientos Penales determina que la acción penal se inicia desde el momento en que el Ministerio Público solicita fecha para la audiencia inicial o simplemente solicita ya sea una orden de comparecencia, o bien, de aprehensión; empero el Código Penal del Estado de Chihuahua sostiene que la prescripción no se interrumpe, sino hasta el momento en que efectivamente el imputado comparece materialmente ante el juzgador o se le ejecuta la orden de aprehensión. Esta diferencia no es menor, ya que debemos ser conscientes de que, cuando el imputado no se encuentra detenido por flagrancia o caso urgente, existe un lapso entre la programación de una audiencia y su verificación, que por disposición legal puede consistir hasta en quince días de distancia desde el momento en que el Ministerio Público solicita fecha para la audiencia inicial, y la verificación de la misma, e incluso suelen materializarse defectos en las notificaciones o citaciones, que prolongan la fecha para la formulación de la imputación, transcurso de tiempo que puede llegar a ser crucial y no debe incluirse en el cómputo de la prescripción de la acción en comento.

\section{El inicio del ejercicio de la pretensión punitiva}

Es importante poner en relieve el contenido del ordinal 211 del Código Nacional de Procedimientos Penales, que establece:

Artículo 211. Etapas del procedimiento penal

El procedimiento penal comprende las siguientes etapas:

I. La de investigación, que comprende las siguientes fases:

a) Investigación inicial, que comienza con la presentación de la denuncia, querella $u$ otro requisito equivalente y concluye cuando el imputado queda a disposición del Juez de control para que se le formule imputación, e b) Investigación complementaria, que comprende desde la formulación de la imputación y se agota una vez que se haya cerrado la investigación;

\section{[...]}

La investigación no se interrumpe ni se suspende durante el tiempo en que se lleve a cabo la audiencia inicial hasta su conclusión o durante la víspera de la ejecución de una orden de aprehensión. El ejercicio de la acción inicia con la solicitud de citatorio a audiencia inicial, puesta a disposición del detenido ante la autoridad judicial o cuando se solicita la orden de aprehensión o comparecencia, 
con lo cual el Ministerio Público no perderá la dirección de la investigación. El proceso dará inicio con la audiencia inicial, y terminará con la sentencia firme.

En efecto, con meridiana claridad, el Congreso de la Unión determinó que la pretensión punitiva de la que el Ministerio Público se encuentra investido, debe tenerse por ejercida:

a) Desde el momento mismo en el que el órgano investigador solicita al Juzgado de Control se programe fecha y hora para la celebración de una audiencia inicial, y se le envíe citación al imputado para que comparezca de manera voluntaria; o bien

b) Desde la sola puesta a disposición de un imputado detenido, por virtud de flagrante delito o caso urgente; o finalmente

c) Desde la sola solicitud (no libramiento, ni ejecución), de una orden de aprehensión o comparecencia.

No pasa inadvertida la distinción que el legislador realiza, con acierto, entre procedimiento y proceso:

a) El procedimiento se inicia desde la presentación de una denuncia, querella o su equivalente.

b) El proceso, en estricto sentido, aunque comienza desde que se verifica la au- diencia inicial, ya sea por puesta a disposición de un detenido por flagrancia o caso urgente, o bien, hasta la presentación del imputado luego de una orden de citación, o bien, por la efectiva ejecución de una orden de aprehensión o comparecencia, no implica que hasta este momento deba tenerse por iniciado el ejercicio de la acción penal.

c) En efecto, en torno al ejercicio de la acción penal de manera deliberada el legislador precisó, en un nuevo paradigma, que se inicia desde que el Ministerio Público solicita el citatorio para la audiencia inicial o, en su caso, las respectivas órdenes de comparecencia o aprehensión. Es decir, que se está ejerciendo la pretensión punitiva desde el momento en que el órgano investigador manifiesta la intención de formular imputación dentro de una audiencia inicial con independencia de que se haya verificado o no la misma. Esta redacción legislativa tiene su razón de ser, tal y como se abundará más adelante.

El ejercicio de la acción penal resulta un aspecto integrante de la función persecutoria, que consiste en un conjunto de gestiones que el Ministerio Público -o excepcionalmente un particular- puede realizar ante el órgano jurisdiccional, para que este aplique la norma punitiva al caso concreto. Se puede concluir que 
esta figura no se agota en un solo momento, sino que se compone de un cúmulo de actuaciones que se inician desde que el Ministerio Público considera que cuenta con datos de prueba aptos y suficientes para solicitar la intervención del órgano jurisdiccional, y en el supuesto de que no exista detención por flagrancia o caso urgente, la pretensión punitiva debe tenerse por iniciada en su ejercicio desde el momento en que se solicita citatorio para la audiencia inicial, se haya verificado o no dicha audiencia.

Esta nueva regla resultó establecida por el legislador rompiendo con el esquema pretérito, que consideraba que la acción penal debía tenerse por efectivamente ejercida hasta que se lograba la comparecencia del imputado ante el entonces denominado juez de Garantía, y se verificaba la formulación de imputación. Sin embargo, esta nueva regla sobre el inicio de la pretensión punitiva ha sido poco difundida, derivado de que hasta el mes de junio de 2016 fue la fecha límite para la declaratoria del inicio de la vigencia en la totalidad del territorio mexicano del Código Nacional de Procedimientos Penales, y, por lo tanto, las carpetas de investigación que se han iniciado bajo el imperio de este nuevo ordenamiento no son de tan antigua data.

Fortalece la interpretación precisada en supralíneas lo expresado por Pereznieto Castro (2019), cuando al explicar el conte- nido del artículo 211 del Código Nacional de Procedimientos Penales, refiere:

Este artículo, de manera expresa señala la diferencia que existe entre procedimiento y proceso penal, exponiendo los momentos en que inicia cada uno. Precisando que el procedimiento penal inicia en el momento en que la autoridad investigadora tiene conocimiento, de un hecho probablemente constitutivo de delito, con la presentación de una denuncia o querella. Mientras que el proceso, comenzará con la audiencia inicial, siendo que esta se podrá verificar cuando la detención en flagrancia o en caso urgente, por cumplimiento de una orden de aprehensión, o bien, cuando el imputado comparezca previa citación a una audiencia de formulación de imputación. Es importante conocer el momento, en que inicia el proceso penal con la finalidad de no rebasar el plazo que tiene el juzgador para resolver el asunto en lo principal con la emisión de una sentencia en el procedimiento ordinario; un procedimiento abreviado, o bien mediante la aplicación de un medio alterno para resolver el conflicto penal. Lo anterior se debe, a que Constitucionalmente se prevé el plazo en que debe ser juzgado de conformidad con el artículo 20, apartado B, fracción VII, de nuestra Carta Magna. También debe destacarse que dicho precepto, precisa el momento 
en que se ejerce la acción penal, el cual es diverso al inicio del procedimiento y del proceso penal (pp. 384 -385).

Lo antes explicado se relaciona con la opinión de García Ramírez e Islas de González Mariscal (2015), al sostener que:

En el sistema acusatorio que regula el CNPP, la investigación es una; comienza a partir de la noticia criminis y se agota a más tardar una vez concluido el plazo que conceda el juez de control para su complementación. No obstante, siendo una, tiene dos fases o momentos destacados (art. 211): a). Antes de que el imputado quede a disposición del juez de control para la formulación de imputación, a la que el CNPP, denomina investigación inicial, y b) A partir de la formulación de la imputación hasta que se haya cerrado la investigación a la que se le llama investigación complementaria. Cabe señalar que la investigación no se interrumpe o suspende durante la víspera de la ejecución de una orden de aprehensión, ni durante la audiencia inicial, hasta su conclusión. Tampoco una vez ejercida la acción penal, la cual inicia con la solicitud de citatorio a audiencia inicial, puesta a disposición del detenido ante el juez de control, o cuando se solicita la orden de aprehensión o comparecencia. En este sentido es de tenerse en cuenta que el ejercicio de la acción penal no se agota en tanto ocurra cualquiera de las actuaciones antes señaladas, sino que se extiende en el tiempo, de allí que, a pesar del inicio del ejercicio de la acción penal, el MP no pierde en lo posterior la dirección de la investigación (art. 211 penúltimo párrafo). [...] El concepto de acción penal, y su ejercicio, es distinto al que se concibe en el sistema tradicional. En el acusatorio no se puede establecer que el MP, ejerce la acción penal en un solo acto - como pudiera ser con la imputación o la solicitud de vinculación a proceso durante la audiencia inicial (pp. 56-60).

Por su parte, Leguízamo Ferrer et al. (2015) sostienen que:

El ejercicio de la acción penal, de conformidad con el nuevo CNPP, se inicia con la solicitud de citatorio para audiencia inicial, con la puesta a disposición del detenido ante la autoridad judicial, o cuando se solicita la orden de aprehensión o comparecencia; pero no obstante que se haya ejercido la acción penal, el Ministerio Público continuará con la dirección de la investigación, como lo precisa el artículo 211 de la nueva legislación procesal.

La autora en cita igualmente explica que el proceso, en estricto sentido, comienza con la celebración de la audiencia inicial, 
pero que el ejercicio de la acción penal por parte del Ministerio Público debe tenerse por iniciado desde el momento antes puntualizado, toda vez que la inclusión de este párrafo obedeció a la insistencia de que esta figura no debía ser olvidada, además de que no había claridad de delimitación entre proceso y procedimiento penal, y cuál era el género (Leguízamo Ferrer et al., 2015, p. 295).

Se abunda deliberadamente sobre el inicio del ejercicio de la acción penal, toda vez que resulta un tópico de toral importancia para abordar la existencia o no de la prescripción de la misma (pretensión punitiva o acción penal). En virtud de que una facultad ya ejercida no debe tenerse por prescrita, toda vez que la prescripción lo que sanciona es el desinterés, la falta de actividad $u$ omisión de la representación social.

Lo anterior independientemente de que la acción penal se ejerza y, a la postre, de manera contingente el imputado llegue a declararse sustraído a la acción de la justicia; toda vez que, con dicha declaración, el efecto producido sería que volvería a correr el plazo prescriptivo desde la declaratoria de la sustracción, plazo que se había interrumpido con el inicio del ejercicio de la pretensión punitiva, como se apuntará en líneas posteriores.

\section{La prescripción y su aspecto material re-} gulado en el Código Penal del Estado de Chihuahua en contraste con el inicio del

\section{ejercicio de la acción penal en el Código Nacional de Procedimientos Penales}

La prescripción es una figura jurídica que implica la pérdida de un derecho, facultad o atribución por no haberlo ejercido o hecho valer, a pesar del transcurso del tiempo. También se debe especificar que la prescripción puede analizarse desde un doble aspecto: uno material o sustantivo y otro relacionado con el enfoque o repercusión adjetiva o procesal. También debe distinguirse que la prescripción puede recaer sobre la acción penal o sobre la facultad de ejecutar las penas o las medidas de seguridad.

Sobre el tema que nos interesa, que es la prescripción de la acción penal, se puede advertir que, en su aspecto material, fue delegada por el Código Nacional de Procedimientos Penales a las legislaturas de los Estados, para efecto de determinar temas como: a) el plazo en el que prescribe la acción penal respecto de las penalidades que le asiste cada delito (término medio aritmético, nunca inferior a tres años); b) a partir de qué momento se comienza a computarse; c) si es posible duplicar los plazos; d) e, incluso, si existen delitos imprescriptibles. ${ }^{3}$ Empero, lo que no debe guardar una relación de dependencia o maternidad con la parte sustantiva, es decir, que

3 No debemos soslayar que en nuestra entidad federativa existen delitos imprescriptibles, que se especifican en el numeral 105 del Código Penal del Estado de Chihuahua. 
no deben quedar sometidas a la legislación sustantiva, son las determinaciones expresas sobre el ejercicio de la acción penal, su inicio y formas de hacerla efectiva o de extinguirse. Si bien es cierto que estos temas cuentan con fuertes puntos de contacto con la suspensión de la prescripción, también lo es que con base en el Principio de Especialidad de las Normas, en cuanto a estos últimos tópicos, debe prevalecer lo establecido en la Codificación Nacional Adjetiva Penal, quedando supeditado el aspecto material de la prescripción de la acción penal, al momento en que se tenga por ejercida, de conformidad con el Código Nacional de Procedimientos Penales.

Para una mejor explicación, el Código Penal del Estado de Chihuahua, desde su numeral 105 hasta el 113, se encarga de regular el aspecto material de la prescripción de la acción penal:

Artículo 105. Efectos y características de la prescripción

La prescripción es personal y extingue la pretensión punitiva y la potestad de ejecutar las penas y las medidas de seguridad, y para ello bastará el transcurso del tiempo señalado por la ley. [...]

Artículo 106. Prescripción de oficio o a petición de parte

La resolución en torno de la prescripción se dictará de oficio o a petición de parte. Artículo 107. Duplicación de los plazos para la prescripción
Los plazos para que opere la prescripción se duplicarán respecto de quienes se encuentren fuera del territorio del Estado, si por esta circunstancia no es posible concluir la investigación, el proceso o la ejecución de la sentencia.

Artículo 108. Plazos para la prescripción de la pretensión punitiva

Los plazos para la prescripción de la pretensión punitiva serán continuos; en ellos se considerará el delito con sus modalidades y se contarán a partir de:

I. El momento en que se consumó el delito, si es instantáneo;

II. El momento en que cesó la consumación, si el delito es permanente; III. El día en que se realizó la última conducta, si el delito es continuado;

IV. El momento en que se realizó el último acto de ejecución o se omitió la conducta debida, si se trata de tentativa; y V. El día en que el Ministerio Público haya recibido el oficio correspondiente, en los casos en que se hubiere librado orden de reaprehensión o presentación, respecto del procesado que se haya sustraído de la acción de la justicia.

Artículo 111. Prescripción según el tipo de pena

La pretensión punitiva respecto de delitos que se investigan de oficio prescribirá: I. En un plazo igual al término medio aritmético de la pena privativa de la libertad, incluidas las modalidades del de- 
lito cometido, pero en ningún caso será menor de tres años.

Esta regla se aplicará cuando la pena privativa de la libertad esté señalada en forma conjunta o alterna con otra diversa.

II. En un año, si el delito se sanciona con pena no privativa de la libertad.

Artículo 112. Prescripción en caso de concurso de delitos

En los casos de concurso ideal de delitos, la pretensión punitiva prescribirá conforme a las reglas para el delito que merezca la pena mayor.

En los casos de concurso real de delitos, los plazos para la prescripción punitiva empezarán a correr simultáneamente y prescribirán separadamente para cada uno de los delitos.

Hasta este punto no existe discrepancia alguna con la figura procesal del ejercicio de la acción penal o la función persecutoria, a la luz de su nueva regulación en el Código Nacional de Procedimientos Penales. Sin embargo, aparecerá en nuestro escenario jurídico el primer párrafo del numeral 114 del Código Penal de Chihuahua, que debe ponerse en relieve cobró vigencia desde el 01 de enero de 2007 y comulgaba con el anterior criterio sobre el ejercicio de la acción penal, establecido en el abrogado Código de Procedimientos Penales del Estado de Chihuahua, que establecía una directriz mucho menos tolerante con la actividad persecutoria, indicando que la prescripción se interrumpía hasta que se verificaba la audiencia de formulación de imputación, extremo que no encuentra vigencia ni asidero jurídico ni disposición semejante en el Código Nacional de Procedimientos Penales.

En la siguiente tabla se plasma, dentro de su columna izquierda, el texto del vigente artículo 114 del Código Penal del Estado de Chihuahua, que tal y como se ha explicado determina tajantemente que la prescripción se interrumpe hasta que el imputado se encuentra presencialmente ante el juez; y en la columna derecha, se presenta al lector el numeral 278 del abrogado Código de Procedimientos Penales del Estado de Chihuahua, que establecía expresamente, en armonía con la parte sustantiva que la prescripción de la acción penal solo se interrumpía hasta que se llevaba a cabo la audiencia de formulación de imputación, es decir, hasta que el imputado estuviera frente al juez de garantía, hoy llamado juez de control: 


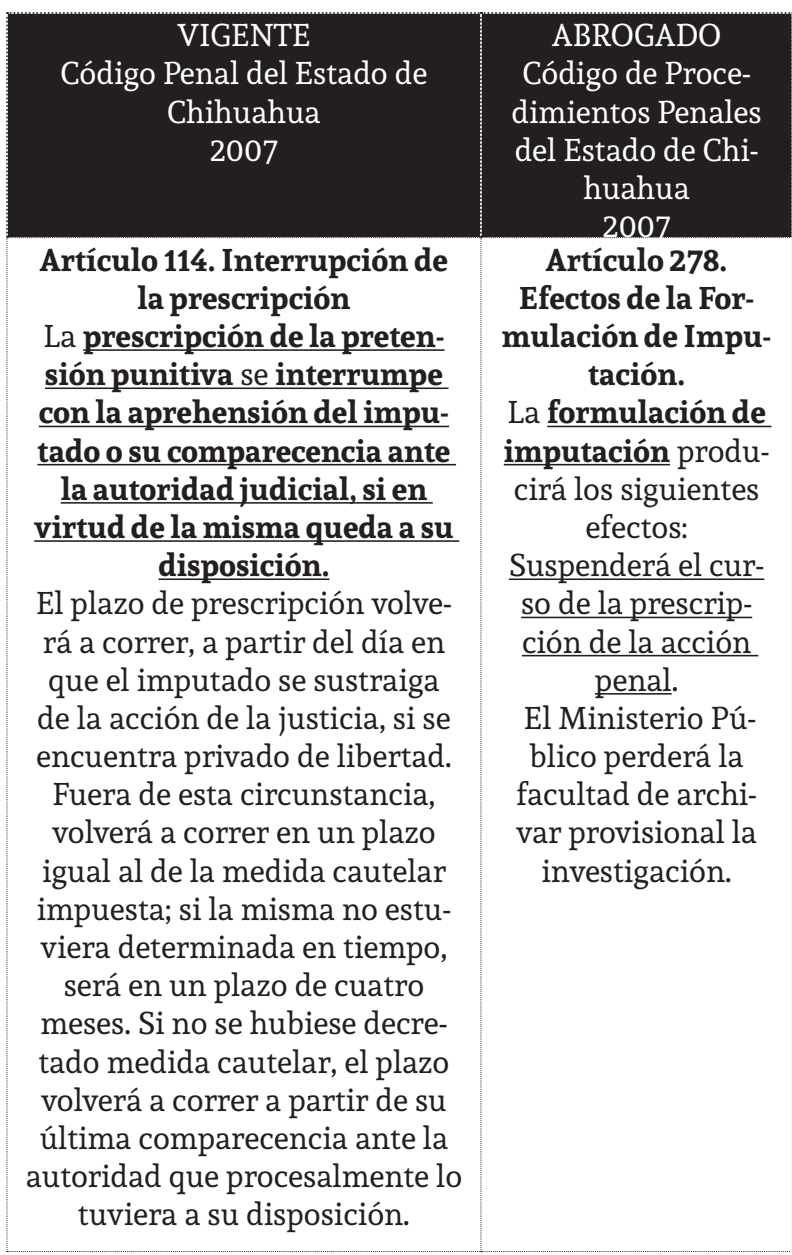

Fuente: (izquierda) Código Penal del Estado de Chihuahua (2007); (derecha) Código de Procedimientos Penales del Estado de Chihuahua (2007) (abrogado).

En efecto, el abrogado Código Adjetivo Penal del Estado de Chihuahua determinaba que solamente hasta que se realizara la formulación de imputación, quedaría suspendida la prescripción de la acción penal, lo que obligaba a incluir en el plazo para el cómputo de la misma todo el tiempo que transcurriera administrativamente para acordar la solicitud del Ministerio Público, la programación y verificación de la audiencia para formular imputación e, incluso, contingencias que pudieran surgir, como casos en los que no se notificaba conforme a derecho a los imputados, e implicaba la reprogramación de la audiencia por defectos en las diligencias de notificación. Por lo tanto, el Congreso de la Unión, al advertir estas contingencias, fue que consideró conveniente crear una disposición expresa en la que se especificara claramente el momento en que el Ministerio Público estaba iniciando con el ejercicio de la acción penal, externando su voluntad de someter el asunto concreto a la intervención del juez de Control, pidiendo el citatorio para audiencia inicial o, como en el presente caso, la orden de comparecencia. Es decir, desde este momento comienza la excitación para que el órgano jurisdiccional aplique la norma al caso concreto.

No resulta accidental que el Congreso de la Unión haya establecido con inexorable claridad los límites entre una etapa y otra del procedimiento penal, y sobre todo la frontera en la cual se tiene por iniciado el proceso, que si bien es cierto se materializa hasta la verificación de la audiencia inicial, también lo es que se precisa que desde la sola solicitud de la audiencia inicial, $u$ orden de comparecencia, debe tenerse iniciado el ejercicio de la acción penal, para efecto de no trasladar las repercusiones en la dilación o retraso de la audiencia inicial al Ministerio Público, pero sobre todo para la víctima u ofendido, a quien le afec- 
taría en su Derecho Humano de Acceso a la Justicia, y la obtención de la reparación integral del daño ocasionado por el delito. Sería inexacto considerar que la letra de la ley no da lugar a mayor interpretación que la aplicación inevitable y taxativa del primer párrafo del artículo 114 del Código Sustantivo Estatal en materia penal. Toda vez que en realidad debe aplicarse el método de interpretación sistemático, es decir, no debemos analizar el artículo 114 del Código Penal del Estado de Chihuahua de manera aislada, sino como parte integrante del sistema del cual forma parte, de tal suerte que, con esta forma de interpretación, debemos de encontrarle sentido al artículo antes mencionado en relación con el numeral 211 del Código Nacional de Procedimientos Penales. Ya que como lo ha explicado el tratadista Rodolfo Vigo (2017), el método sistemático aplicado a la interpretación jurídica se refiere a la conexión interna que enlaza a todas las instituciones y reglas jurídicas dentro de una magna unidad (p. 48). Lo anterior implica analizar y encontrarle sentido a una determinación legal, no solo por su texto individual sino en relación con el resto de las disposiciones contenidas, tanto en el código al que pertenece como en el resto de cuerpos normativos que existen en el sistema jurídico al que pertenece, para efecto de lograr mantener la coherencia de este.
Esta forma de interpretación y aplicación de la norma jurídica busca extraer del texto legal un significado que sea acorde con el contenido general de los ordenamientos a los que pertenece, es decir, procura el significado atendiendo al conjunto de normas o sistema del que forma parte, lo que se traduce en no interpretar el contenido del artículo 114 del Código Penal del Estado de Chihuahua de manera individual, sino en conjunto con los demás preceptos que forman parte del sistema penal mexicano, tanto sustantivo como adjetivo, lo que irrefragablemente nos lleva al entendimiento del antagonismo que existe entre la obsoleta regla del artículo 114 del Código Penal chihuahuense y la nueva regulación sobre el inicio del ejercicio de la acción penal prevista en el arábigo 211 del Código Nacional de Procedimientos Penales, debiendo prevalecer este último por las razones que más adelante se apuntarán de manera pormenorizada.

Resulta evidente que para estos mismos efectos existe la disposición que, sin margen de duda, nos indica todas las etapas del procedimiento, el inicio del proceso y de la acción penal, que acontecen en momentos diversos. Por decirlo de manera simple: el inicio del ejercicio de la acción penal comienza aun antes de que se formalice el proceso en estricto sentido; es el puente que conecta a la investigación inicial con la complementaria. 
Habiéndose puesto en relieve la discrepancia que existe entre las disposiciones antes puntualizadas con la finalidad de restaurar la armonía o coherencia del sistema y la racionalidad legislativa, como lo desarrolla Anchondo Paredes (2012), en una interpretación sistemática, se pueden seguir tres reglas ${ }^{4}$ (p. 44):

a) Criterio cronológico. La norma posterior prevalece sobre la anterior. En este caso, el cuerpo normativo de más reciente generación es el Código Nacional de Procedimientos Penales, superando al Código Penal del Estado de Chihuahua, y su restrictiva disposición contenida en el primer parágrafo de su artículo 114, que más bien guardaba relación directa con una disposición abrogada y superada, como lo era el numeral 278 del Código de Procedimientos Penales del Estado de Chihuahua.

b) Criterio jerárquico. La norma superior debe sobreponerse a la inferior. En el presente caso, el criterio sobre el momento en que se inicia del ejercicio de la acción penal, y por lo tanto se deja de

4 Métodos interpretativos que sirven de solución para antinomias dentro de un sistema; se fortalece su utilidad, además de lo expuesto por el autor en cita, con el siguiente criterio publicado en: Semanario Judicial de la Federación y su Gaceta, Tomo XXXI, febrero de 2010, Tesis: I.40.C.220 C, Página: 2788, Epoca: Novena Epoca, Registro: 165344, Instancia: Tribunales Colegiados de Circuito, Tipo de Tesis: Aislada, ANTINOMIAS O CONFLICTOS DE LEYES. CRITERIOS DE SOLUCION. computar el plazo de la prescripción, no fue delegado por el Congreso de la Unión a las legislaturas de los Estados; esa es la razón de ser del artículo 211 del Código Nacional de Procedimientos Penales.

c) Criterio de especialidad. La disposición más especializada, clara y precisa prevalece sobre la general. En el presente caso, aun y cuando el aspecto material de la prescripción se encuentra especialmente delegado a la parte sustantiva del derecho penal, su impacto sobre el ejercicio de la acción penal y la interrupción de esta, deben estarse a lo establecido en el Código Nacional de Procedimientos Penales. Es decir, el Código Penal chihuahuense no debe imponerle al Código Nacional de Procedimientos Penales el criterio sobre el momento en que debe tenerse por iniciada la pretensión punitiva, y consecuentemente suspendida la prescripción; en este solo aspecto, por su repercusión procesal, implica que la norma especializada sobre el inicio de la acción penal sea el Código Adjetivo.

Un sistema jurídico debe tener una lógica interna, armonía y coherencia (Tardif, 2016, p. 24), que en algún momento tuvo el artículo 114 del Código Penal del Estado de Chihuahua, cuando se encontraba vigente el extinto numeral 278 del Código de Procedimientos Penales de esta 
misma entidad. Sin embargo, la lógica del artículo 114 del CPCH se perdió cuando entró en vigor el nuevo criterio del Código Nacional de Procedimientos Penales. Una antinomia puede ser explicada como una dificultad o anomalía en el Principio de Compatibilidad que deben de cumplir las normas dentro de un sistema jurídico. Álvarez Ledesma (2010) explica como

[...] el principio de compatibilidad con que deben de cumplir las normas que conforman los sistemas jurídicos, constituye una salvaguarda de la unidad y coherencia de los ordenamientos jurídicos y, en consecuencia, de dos valores instrumentales del derecho: el orden y la seguridad. [...] es claro entonces que la aplicación del derecho puede encontrar como una de sus dificultades particulares la existencia de normas contradictorias, es decir, antinomias.

Cuando para resolver un problema el juez tiene frente a sí normas contradictorias - una que prohíbe y otra que permite una misma situación - la ya difícil tarea de juzgar se complica, pues el ordenamiento resulta incoherente. El juez, como se señaló arriba, deberá hacer prevalecer una de las normas (pp. 273-273).

Por lo que la forma de resolver dicha antinomia es ponderando y haciendo prevalecer el Código Nacional de Procedimientos Penales, ya que, de esa forma, se cumple con los objetivos que establece el artículo 20, apartado A, fracción I de la Constitución Política de los Estados Unidos Mexicanos:

Artículo 20. El proceso penal será acusatorio y oral. Se regirá por los principios de publicidad, contradicción, concentración, continuidad e inmediación.

A. De los principios generales:

I. El proceso penal tendrá por objeto el esclarecimiento de los hechos, proteger al inocente, procurar que el culpable no quede impune y que los daños causados por el delito se reparen; [...]

En este orden de ideas, en el razonamiento jurisdiccional podremos advertir cómo es que la prescripción encuentra su base en la seguridad jurídica, es decir, impedir que una persona se encuentre indefinidamente sujeta a investigación o persecución penal, estableciendo plazos de acuerdo con la magnitud de la pena que pudiera llegarse a imponer en un caso concreto. Sin embargo, frente a este principio de seguridad jurídica se encuentra el derecho humano de acceso a la justicia de las víctimas u ofendidos, así como el derecho a la reparación integral del daño.

Como se presenta, "[...]la ley de ponderación precisa que la intervención en un derecho fundamental solo se justifica por la importancia o peso de satisfacer otro $u$ otros derechos fundamentales, compen- 
sando la medida" (Castañeda Hernández, 2017, p. 81). En este orden de ideas, no consideramos que la figura de la prescripción deba desaparecer; por el contrario, resulta inexorable por seguridad jurídica que exista un límite temporal a la facultad persecutora del Estado. Se considera impreciso establecer que la prescripción deba seguirse computando, aun cuando el Ministerio Público haya iniciado con el ejercicio de la acción penal. Es decir, no debe incluirse dentro del plazo de la prescripción el tiempo que transcurra entre la solicitud de la audiencia inicial y la fecha en que efectivamente logra verificarse, toda vez que esto queda fuera del alcance, tanto del órgano persecutor como de la víctima $u$ ofendido, afectando el derecho fundamental de reparación del daño y acceso a la justicia, como se abundará más adelante.

El método de interpretación histórica, aplicado a las reglas sobre la prescripción del ejercicio de la acción penal, y correlativamente el inicio de la pretensión punitiva, apoyan los argumentos esgrimidos, toda vez que esta técnica estudia los contextos o forma en que una figura jurídica se ha desarrollado a través del tiempo. Es decir, la forma en que los legisladores han abordado a lo largo de la historia una institución jurídica, sin que la juez de Control se haya percatado de que ya no existe una disposición en el Código Nacional de Procedimientos Penales que sostenga que la prescripción de la acción penal deba te- nerse por interrumpida hasta el momento preciso y riguroso en que se tenga formalmente formulada la imputación.

Por el contrario, en una disposición especial, consciente, deliberada y direccionada a evitar estos incidentes prescriptivos, el Congreso de la Unión destacó que, aun cuando el proceso en estricto sentido comience hasta el desarrollo de la audiencia inicial, la acción penal debe tenerse por iniciada en su ejercicio desde la solicitud de la audiencia o de la orden de comparecencia, como en el presente caso la a quo soslayó de manera ilegal, aplicando irreflexiva y mecánicamente el ya superado artículo 114 del Código Penal del Estado de Chihuahua, sin considerar el espíritu del legislador nacional al regular el inicio de la acción penal.

Si se reflexiona con detenimiento no existe otra razón para que el Congreso de la Unión haya establecido el momento en que debe tenerse iniciado el ejercicio de la acción penal que el de tener por interrumpida la prescripción de esta. De no ser así, hubiese bastado con indicar en qué momento se iniciaba el proceso en estricto sentido, es decir, con el desarrollo de la audiencia inicial, y de esta forma seguir con la inercia consistente en que la prescripción de la acción solo se interrumpía con la formulación de imputación.

Al tenor de lo establecido en el artículo 141 del Código Nacional de Procedimientos 
Penales, la regla general, ante la ausencia de flagrancia o caso urgente, consiste en:

a) Dirigir orden de citación al imputado para que comparezca a una audiencia inicial.

b) Incumplida la orden de citación, se debe solicitar una orden de comparecencia para que se haga comparecer coactivamente al imputado.

c) Evadida la orden de comparecencia, solicitarse una orden de aprehensión.

Los anteriores son pasos o directrices generales, que van eslabonados o concatenados unos con otros; por lo tanto, desde la primera de las solicitudes aludidas debe tenerse por iniciado el ejercicio de la acción penal y, por lo tanto, interrumpida la prescripción. Lo que no transgrede el Principio de Seguridad Jurídica, puesto que no se coloca en pendencia indefinida, o sine die, la acción penal al caso concreto, toda vez que el Ministerio Público ya se encuentra haciendo valer la facultad que le otorga por excelencia el arábigo 21 de la Constitución Política de los Estados Unidos Mexicanos.

En una interpretación sistemática, y en apego al Principio de Especialidad de las Normas Sustantivas y Adjetivas, debe de considerarse que el artículo 114 del Código Penal del Estado de Chihuahua tuvo su origen armonizando con disposiciones procesales que a la fecha no se encuentran vigentes. Por lo tanto, deben de prevalecer las reglas para el ejercicio de la acción penal que establece el numeral 211 del Código Nacional de Procedimientos Penales en relación con lo establecido por el dispositivo 485 fracción vil del mismo ordenamiento.

En la siguiente tabla comparativa, se pone en evidencia de una manera más visual o ilustrativa. La colisión entre el artículo 211 del Código Nacional de Procedimientos Penales tiene por ejercida la acción penal desde la solicitud de citatoria para la audiencia inicial (formulación de imputación), independientemente de que el imputado comparezca a la misma. El numeral 114 del Código Penal del Estado de Chihuahua permite que se extinga la acción penal o pretensión punitiva mientras no se logre la comparecencia del imputado ante el juez, lo que provoca un conflicto, ya que una facultad ya ejercida - como la acción penal- no debe tenerse por prescrita. Asimismo, se incluye un comparativo de los numerales 92 del Código Sustantivo y 485 del Código Adjetivo, toda vez que ambos pretenden regular las causas de extinción de la acción penal o pretensión punitiva de la siguiente manera: 
Código Penal del Estado de Chihuahua, que guardaba coherencia con el extinto artículo 278 del Código de Procedimientos Penales del Estado de Chihuahua.

Artículo 114. Interrupción de la prescripción La prescripción de la pretensión punitiva se interrumpe con la aprehensión del imputado o su comparecencia ante la autoridad judicial, si en virtud de la misma queda a su disposición. El plazo de prescripción volverá a correr, a partir del día en que el imputado se sustraiga de la acción de la justicia, si se encuentra privado de libertad. Fuera de esta circunstancia, volverá a correr en un plazo igual al de la medida cautelar impuesta; si la misma no estuviera determinada en tiempo, será en un plazo de cuatro meses. Si no se hubiese decretado medida cautelar, el plazo volverá a correr a partir de su última comparecencia ante la autoridad que procesalmente lo tuviera a su disposición.

Código Nacional de Procedimientos Penales, que no sigue el criterio del artículo 278 del abrogado CPPCH, y precisa el momento en que debe tenerse iniciada la acción penal.

Artículo 211. Etapas del procedimiento penal

El procedimiento penal comprende las siguientes etapas:

I. La de investigación, que comprende las siguientes fases: a) Investigación inicial, que comienza con la presentación de la denuncia, querella u otro requisito equivalente y concluye cuando el imputado queda a disposición del Juez de control para que se le formule imputación, e

b) Investigación complementaria, que comprende desde la formulación de la imputación y se agota una vez que se haya cerrado la investigación;

[...]

La investigación no se interrumpe ni se suspende durante el tiempo en que se lleve a cabo la audiencia inicial hasta su conclusión o durante la víspera de la ejecución de una orden de aprehensión. El ejercicio de la acción inicia con la solicitud de citatorio a audiencia inicial, puesta a disposición del detenido ante la autoridad judicial o cuando se solicita la orden de aprehensión o comparecencia, con lo cual el Ministerio Público no perderá la dirección de la investigación.

El proceso dará inicio con la audiencia inicial, y terminará con la sentencia firme.

Artículo 92. Causas de extinción

La pretensión punitiva y la potestad para ejecutar las penas y medidas de seguridad, se extinguen por:

I. Cumplimiento de la pena o medida de seguridad; II. Muerte del imputado o sentenciado; III. Reconocimiento de la inocencia del sentenciado;

IV. Perdón del ofendido en los delitos de querella o por cualquier otro acto equivalente; V. Rehabilitación;

VI. Conclusión del tratamiento de inimputables; VII. Indulto; VIII. Amnistía; IX. Prescripción; X. Supresión del tipo penal;

XI. Existencia de una sentencia anterior dictada en proceso seguido por los mismos hechos; y XII. Las demás que se establezcan en la ley.
Artículo 485. Causas de extinción de la acción penal La pretensión punitiva y la potestad para ejecutar las penas y medidas de seguridad se extinguirán por las siguientes causas:

I. Cumplimiento de la pena o medida de seguridad;

II. Muerte del acusado o sentenciado;

III. Reconocimiento de inocencia del sentenciado o anulación de la sentencia;

IV. Perdón de la persona ofendida en los delitos de querella o por cualquier otro acto equivalente;
V. Indulto;
VI. Amnistía;

VII. Prescripción;

VIII. Supresión del tipo penal;

IX. Existencia de una sentencia anterior dictada en proceso instaurado por los mismos hechos, o

X. El cumplimiento del criterio de oportunidad o la solución alterna correspondiente.

Fuente: (izquierda) Código Penal del Estado de Chihuahua; (derecha) Código Nacional de Procedimientos

Penales.

En esta tesitura, se puede puntualizar que la parte sustantiva se especializa en la definición de la figura jurídica de la prescripción, pero no se especializa ni debe prevalecer en la regulación de la pretensión punitiva, en particular respecto del momento en que debe tenerse por iniciado su ejercicio y sus formas de extinción, 
por lo que consideramos que deben prevalecer los numerales 211 y 485 del Código Nacional de Procedimientos Penales.

\section{Notas conclusivas}

Una antinomia es una anomalía dentro de un sistema jurídico, toda vez que este último debe caracterizarse por la lógica y la coherencia entre sus normas. La existencia de normas contradictorias dentro de un sistema complica la labor jurisdiccional y puede ser un obstáculo para el acceso a la justicia. Mientras no se logre una reforma que regrese la armonía perdida por normas contradictorias, debemos auxiliarnos de métodos interpretativos, como el sistemático y sus criterios cronológicos, jerárquico y de especialidad.

El artículo 114 del Código Penal del Estado de Chihuahua genera un conflicto con el numeral 211 del Código Nacional de Procedimientos Penales, toda vez que el primero permite que la acción penal prescriba, aun cuando ya ha sido ejercida en los términos del último de los ordinales mencionados. Por lo que el Código Penal chihuahuense debe ser reformado con la finalidad de guardar coherencia y precisar que la prescripción de la acción penal, se suspenderá desde el momento en que el Ministerio Público la ejerce en los términos del Código procesal de la materia, es decir, cuando solicita citatorio para la audiencia inicial, orden de comparecencia, aprehensión o, en su caso, con la puesta a disposición del detenido, y no hasta el momento en que se verifica la audiencia inicial, en particular la formulación de imputación. ${ }^{5}$

Determinar que la acción penal puede prescribir, aun cuando ya se ha ejercido, afecta al derecho humano de acceso a la justicia de las víctimas u ofendidos del delito. Por lo tanto, el primer parágrafo del artículo 114 del Código Penal del Estado de Chihuahua debe reformarse para especificar que una vez ejercida la acción penal, deberá de dejarse de computar el plazo prescriptivo, que volverá a correr solamente en caso de que el imputado se sustraiga a la acción de la justicia.

La propuesta de reforma antes puntualizada fortalece el derecho humano de acceso a la justicia para las víctimas u ofendidos con un enfoque preferencial para lograr la reparación integral del daño y respeta el derecho fundamental del im-

5 Infortunadamente la Suprema Corte de Justicia de la Nación aún no se ha pronunciado sobre este problema, ya que solo existe un muy reciente criterio aislado que emana de los Tribunales Colegiados de Circuito, que si bien es cierto no resulta obligatorio, también lo es que orienta en el caso concreto y confirma la postura que expone este autor en el presente artículo: Epoca: Décima Epoca, Registro: 2021386, Instancia: Tribunales Colegiados de Circuito, Tipo de Tesis: Aislada, Fuente: Gaceta del Semanario Judicial de la Federación, Libro 74, Enero de 2020, Tomo III, Materia(s): Penal, Tesis: VI.2o.P.62 P (10a.), Página: 2629. PRESCRIPCION DE LA ACCION PENAL. EL COMPUTO DEL PLAZO PARA QUE OPERE SE INTERRUMPE POR EL EJERCICIO DE LA ACCION PENAL, QUE DA INICIO SÓLO EN CUALQUIERA DE LAS HIPOTESIS DEFINIDAS EN EL ARTICULO 211 DEL CODIGO NACIONAL DE PROCEDIMIENTOS PENALES Y NO CON LA SOLICITUD DE AUDIENCIA PARA DIRIMIR LA COMPETENCIA DEL JUEZ DE CONTROL. 
putado para ser oído y vencido en juicio. Así como el Principio de Seguridad Jurídica, ya que no se incluye en el plazo de la prescripción todo el tiempo que demore el tribunal en programar la audiencia inicial una vez que ha sido solicitada por el Ministerio Público ni tampoco el tiempo que se pueda perder por dilaciones que se encuentren fuera del alcance de la víctima o del órgano persecutor. ${ }^{6}$

\section{Referencias}

\section{Bibliográficas}

Álvarez Ledesma, M. I. (2010). Introducción al Derecho (2. ${ }^{\mathrm{a}}$ ed.). McGraw-Hill.

Castañeda Hernández, M. (2017). El principio pro persona ante la ponderación de derechos. Comisión Nacional de los Derechos Humanos.

6 Sirve de apoyo para este argumento el contenido del siguiente criterio que emana de los Tribunales Colegiados de Circuito, que si bien no es jurisprudencia, resulta orientador en la especie: Epoca: Décima Epoca, Registro: 2004056, Instancia: Tribunales Colegiados de Circuito, Tipo de Tesis: Aislada, Fuente: Semanario Judicial de la Federación y su Gaceta, Libro XXII, Julio de 2013, Tomo 2, Materia(s): Constitucional, Penal, Tesis: VIII.1o.(X Región) 1 P (10a.), Página: 1522. PRESCRIPCION DE LA ACCION PENAL. EL ARTICULO 171, ULTIMO PARRAFO, DEL CODIGO PENAL DE COAHUILA, VIGENTE HASTA EL 17 DE MAYO DE 2013, AL ESTABLECER QUE NO SE INTERRUMPIRA NI SE SUSPENDERA CON SU EJERCICIO, NI CON LA PETICIÓN DE ORDEN DE APREHENSION O DE COMPARECENCIA, ES INCONVENCIONAL POR INFRINGIR LOS PRINCIPIOS CONTENIDOS EN LOS ARTICULOS 8, NUMERAL 1 Y 25 DE LA CONVENCION AMERICANA SOBRE DERECHOS HUMANOS - se recomienda dar lectura íntegra al presente criterio.
García Ramírez, S., \& Islas de González Mariscal, O. (2015). El Código Nacional de Procedimientos Penales. Estudios. Instituto de Investigaciones Jurídicas de la Universidad Nacional Autónoma de México.

Leguízamo Ferrer, M. E. et al. (2015). Comentarios al Código Nacional de Procedimientos Penales. UBIJUs.

Martínez Morales, R. (2014). Diccionario Jurídico Contemporáneo. Iure Editores.

Pereznieto Castro, L. (2019). Código Nacional de Procedimientos Penales. Tirant lo Blanch.

Rivera Silva, M. (2005). El procedimiento penal (34. ed.). Porrúa.

Tardif, É. (2016). Sistemas jurídicos contemporáneos. Derecho comparado (p. 24). Limusa.

Vela Treviño, S. (1990). La prescripción en materia penal. Trillas.

Vigo, R. (2017). La interpretación (argumentación) jurídica en el Estado de Derecho Constitucional. Tirant lo Blanch.

Hemerográficas

Anchondo Paredes, V. E. (2012). Métodos de interpretación jurídica. Quid Iuris, 16, 44.

Legislativas

Código Nacional de Procedimientos Penales.

Código Penal del Estado de Chihuahua. Código de Procedimientos Penales del Estado de Chihuahua.

Constitución Política de los Estados Unidos Mexicanos. 